\title{
Burden of illness of trigeminal neuralgia among patients managed in a specialist center in England
}

\author{
Lasair O'Callaghan ${ }^{1 *}$ (D) Lysbeth Floden², Lisa Vinikoor-Imler ${ }^{1}$, Tara Symonds ${ }^{3}$, Kathryn Giblin ${ }^{4}$, Chris Hartford ${ }^{2}$ and \\ Joanna M. Zakrzewska,6
}

\begin{abstract}
Background: Trigeminal neuralgia (TN) causes severe episodic, unilateral facial pain and is initially treated with antiepileptic medications. For patients not responding or intolerant to medications, surgery is an option.

Methods: In order to expand understanding of the pain-related burden of illness associated with TN, a cross-sectional survey was conducted of patients at a specialist center that utilizes a multidisciplinary care pathway. Participants provided information regarding their pain experience and treatment history, and completed several patient-reported outcome (PRO) measures.

Results: Of 129 respondents, 69/128 (54\%; 1 missing) reported no pain in the past 4 weeks. However, 84 (65\%) respondents were on medications, including 49 (38\%) on monotherapy and 35 (27\%) on polytherapy. A proportion of patients had discontinued at least one medication in the past, mostly due to lack of efficacy $(n=62,48 \%)$ and side effects $(n=51,40 \%)$. A total of $52(40 \%)$ patients had undergone surgery, of whom 30 had microvascular decompression (MVD). Although surgery, especially MVD, provided satisfactory pain control in many patients, 29\% of post-surgical patients reported complications, 19\% had pain worsen or stay the same, 48\% were still taking pain medications for $\mathrm{TN}$, and $33 \%$ reported new and different facial pain.
\end{abstract}

Conclusions: In most PRO measures, respondents with current pain interference had poorer scores than those without pain interference. In the Patient Global Impression of Change, 79\% expressed improvement since beginning of treatment at this clinic. These results indicate that while the multidisciplinary approach can substantially alleviate the impact of TN, there remains an unmet medical need for additional treatment options.

Keywords: Trigeminal neuralgia, Trigeminal nerve, Facial pain, Microvascular decompression, Multidisciplinary approach, Patient related outcomes

\section{Background}

Trigeminal neuralgia (TN) is a rare condition that affects the trigeminal nerve, resulting in extreme, sporadic, sudden, electric shock-like unilateral facial pain [1]. The attacks typically last only for a few seconds to a maximum of $2 \mathrm{~min}$ and can occur in quick succession with a frequency of 1-

\footnotetext{
* Correspondence: lasair.ocallaghan@biogen.com

'Biogen, 225 Binney St, Cambridge, MA 02142, USA

Full list of author information is available at the end of the article
}

50/day [2]. These episodes of TN, encompassing the duration of recurrent attacks, can last for periods of days to even months, but can go into periods of remission which can last for months [3]. The condition occurs most frequently in people over 50 years of age, and is more prevalent in women than in men [4]. The intensity and unpredictability of the pain can be physically and mentally incapacitating, and result in a severe burden of illness (BOI) and impaired patient quality of life (QoL) $[5,6]$. Further,

(c) The Author(s). 2020 Open Access This article is licensed under a Creative Commons Attribution 4.0 International License, which permits use, sharing, adaptation, distribution and reproduction in any medium or format, as long as you give appropriate credit to the original author(s) and the source, provide a link to the Creative Commons licence, and indicate if changes were made. The images or other third party material in this article are included in the article's Creative Commons licence, unless indicated otherwise in a credit line to the material. If material is not included in the article's Creative Commons licence and your intended use is not permitted by statutory regulation or exceeds the permitted use, you will need to obtain permission directly from the copyright holder. To view a copy of this licence, visit http://creativecommons.org/licenses/by/4.0/ The Creative Commons Public Domain Dedication waiver (http://creativecommons.org/publicdomain/zero/1.0/) applies to the data made available in this article, unless otherwise stated in a credit line to the data. 
diagnostic delays [7], suboptimal management strategies, complications from treatments, and resistance to treatment may contribute to the disease burden [6].

Recently, TN was classified into 3 categories: classical (primary), in which vascular compression of the nerve with morphological changes in the trigeminal root is observed; secondary, in which major neurologic disease such as multiple sclerosis or tumor of the cerebellopontine angle has been identified; and idiopathic, in which no cause has been found $[2,8]$.

Primary treatment for TN has been pharmacological therapy, with the antiepileptic drugs (AEDs) carbamazepine and oxcarbazepine being first-line [8]; a range of other AEDs such as lamotrigine pregabalin, gabapentin, phenytoin, and baclofen are utilized when first-line drugs are ineffective or contraindicated [8]. However, large claims studies in the USA and smaller studies in Europe show frequent change of medication, suggesting poor efficacy and/or poor tolerability [9-11]. In addition, common side effects of these drugs in the TN population include significant cognitive impairment [12]. For patients non-responsive or intolerant to medications, surgery may be an option, with microvascular decompression (MVD) regarded as the most effective procedure [8]. Although neurosurgical procedures in selected TN patients can produce excellent results, it is not clear which patients will have good outcomes, as studies that have examined factors contributing to surgical outcomes have been limited [8].

There is considerable evidence that $\mathrm{TN}$ has a significant impact on QoL $[5,10,13]$. The natural history of TN has generally been considered progressive, with few remission periods and increasingly longer and more intense relapses gradually becoming less responsive to AEDs [14, 15]. However, recent studies suggest that patients managed in specialist centers utilizing a multidisciplinary approach may experience disease stabilization, and even improvement $[5,9,10,16,17]$.

The current study is a cross-sectional component of a longitudinal survey project, and consists of assessments performed at a single timepoint, in a cohort of patients receiving a high level of clinical care at a specialist facility which has been managing TN patients over several years using a multidisciplinary care pathway. The aim of this study was to gain increased insight into the BOI of $\mathrm{TN}$ by looking at medication use, surgery, pain experience and quality of life as measured by several PROs, and to determine whether current treatments are meeting patient needs. The welldocumented and consistently recorded medical and therapeutic history of these patients allowed a high level of specificity and accuracy in the analysis of the results.

\section{Methods}

\section{Patient recruitment}

Patients were recruited for the study in 2018 from a dedicated multidisciplinary facial pain clinic within a London teaching hospital. At this facility, if patients are taking medication(s), reviews are every 6 months on average; patients may be discharged if they are no longer taking medications following surgery. This single-site patient population has been managed longitudinally since 2007 in a specialized multidisciplinary team model, with access to physicians, dentists, clinical psychologists, a clinical nurse specialist, a neurologist and 3 neurosurgeons. The multidisciplinary team follows the hospital-approved guidelines, which are based on published guidelines for TN [18]. Patients at the facility are clinically contacted a minimum of twice yearly, either face to face, or by telephone by a clinical nurse specialist [17].

Patients were initially contacted and informed of the study by a member of the multidisciplinary team. Patients who were able to be contacted and were reported to have primary $\mathrm{TN}$ were invited to complete the survey. This was the first time they were being asked by the multidisciplinary facial pain clinic to complete a survey electronically.

\section{Survey methodology}

This cross-sectional survey was deployed using a webbased system. If patients were unwilling or unable to complete the online form, they were offered a paper version of the survey. The survey included items about pain interference, history and experience of medication use, history and experience of surgery related to $\mathrm{TN}$, and 5 PRO measures. The 5 PRO measures were: 1) The PennFacial Pain Scale-Revised (PENN-FPS-R), an instrument to assess patient-reported impact of facial pain, was used to inform pain status and the interference of facial pain with patients' activities of daily living (ADLs) during the past week, including general activity, walking, work, mood, enjoyment of life, relations with others, and sleep [19]; 2) The Patient Global Impression of Change (PGIC) [20] was used to evaluate patients' perception of change in health compared to start of treatment; 3) The EQ-5D-5L (EuroQol-5 Dimension-5 Level) was used to evaluate health utility using the UK value set and the EQ-VAS (EuroQol Visual Analog Scale) of the EQ-5D-5L was used to evaluate global health status on the day of the survey; 4) the Brief Pain Inventory - Short Form (BPI-SF) was used to assess level of pain and general pain interference in the last $24 \mathrm{~h}$ [21]; 5) Depression and anxiety over the last week was assessed with the Hospital Anxiety and Depression Scale (HADS) [22].

\section{Data analysis}

Descriptive analyses were used to report demographic and health information, patient-reported pain experience, treatment history and PRO instrument scores. Stratifications were made based on pain status, current medication use (monotherapy/polytherapy/no current meds), and surgery. For the surgical stratification, patients were classified 
as (1) "microvascular decompression (MVD) only" if having one or more MVD procedures but no non-MVD procedures for TN; (2) "Ablative surgery" if having one or more ablative procedures such as gamma knife, radiofrequency thermocoagulation, including stereotactic radiosurgery, but no MVD procedures; (3) "MVD + ablative surgery" if having procedures of both types, or (4) no surgery. Quantitative analyses were performed using SAS software (SAS Institute, Cary, USA).

\section{Results}

\section{Study participants and demographics}

A cohort of 235 patients were initially screened for the study, of whom 195 (female 124; male 70; 1 missing) were invited to participate. Of them, 21 declined, and 174 patients (female 111; male 63) initially agreed to participate. Patients could either complete an online survey or, if they requested, were sent a paper survey. Ultimately, a total of 129 patients completed and returned usable patient surveys, which formed the basis of the analyses (Fig. 1).

Participants had been treated at this clinic for an average of over 6 years, and had an average of over 12 years since their first recorded attack.

Of the respondents, the majority were female (65\%), White $(88 \%)$, married $(71 \%), \geq 65$ years $(60 \%)$ and retired (56\%) (Table 1). The age of respondents ranged from 39 to 85 years; the mean age was 65.7 years; median age was 67 years. Demographic characteristics are reported overall, by current pain experience, current medication use, and surgical history. There were no substantial differences between respondents and non-respondents with regards to mean age; however, among invitees, a higher percentage of those over 55 years old responded compared to younger patients. The response rate for invitees was $66 \%$
(129/195); for those who received the survey, the participation rate was $74 \%(129 / 174) ; 64 \%(111 / 174)$ were female, and of this population $76 \%(84 / 111)$ responded. Overall, 68\% (84/124) of female invitees and 64\% (45/70) of male invitees participated. The male response rate among survey recipients was $71 \%(45 / 63)$.

\section{Pain prevalence}

Among respondents, over half $(69 / 128 ; 54 \%)$ reported that they had not experienced pain in the past 4 weeks. However, only 50 patients scored a zero on the Penn-FPS-R measure, indicating no pain interference. Of the 69 who reported not experiencing pain in the past 4 weeks, 37 (54\%) patients were currently not on any medication and $38(55 \%)$ had undergone 1 or more surgical procedures (Table 2). Of those who reported pain episodes in the previous 4 weeks, the most common triggers were movement of the mouth (including talking) (35\%), and ADLs (including face touching) (33\%), however, just over a quarter (26\%) of respondents reported spontaneous occurrence of pain.

\section{Treatment history \\ Medications}

All patients had taken medication for their TN pain; the most common medications taken by patients were carbamazepine and oxcarbazepine (Table 3). Other AEDs such as lamotrigine, pregabalin, and gabapentin were the next most frequently used. While some patients reported taking opioids or non-steroidal anti-inflammatory drugs during the course of their disease, these medications were not prescribed at the specialist center.

Over the course of treatment, patients had taken a mean of 3.7 medications with a range of 1-13 (Table 4).

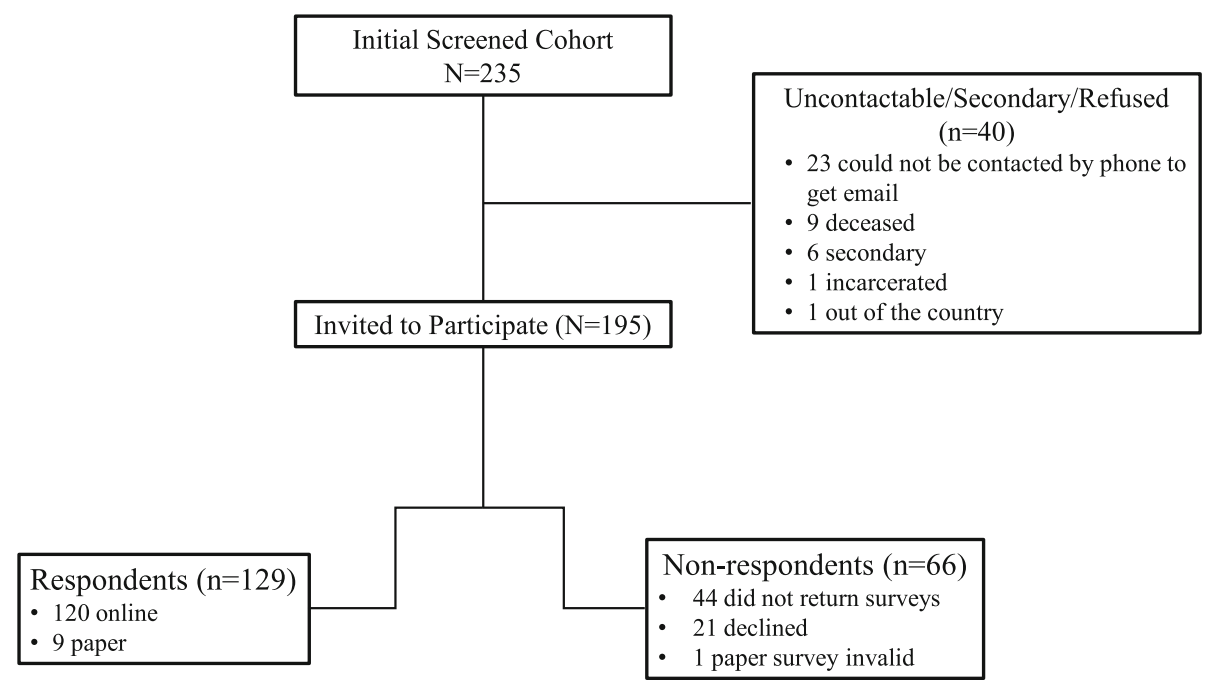

Fig. 1 Survey Response Results 
Table 1 TN Patient Demographics Stratified by Pain, Medication Use, and Surgical History ${ }^{\mathrm{a}}$

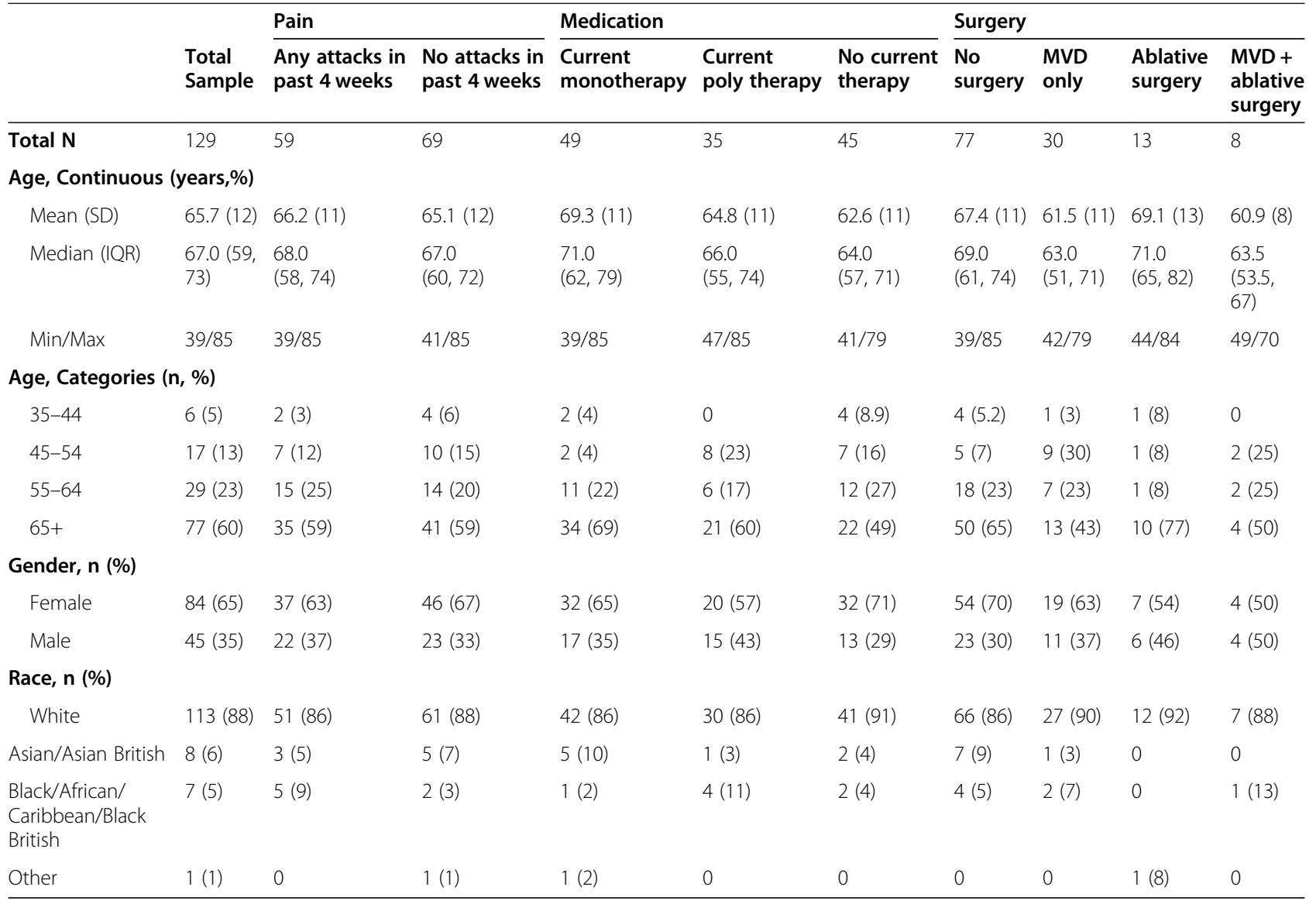

${ }^{a}$ Missing $n=1$ in some pain report and some surgery statistics

MVD Microvascular decompression

Current mean medication use per patient was 1.1 medications, with some patients currently taking up to 5 medications. At the time of survey completion, 84/129 (65\%) patients were on medication, with $49(38 \%)$ on monotherapy and 35 (27\%) on polytherapy of 2 or more medications; 45/129 (35\%) were using no medications.

\section{Surgery}

A total of 52/129 (40\%) patients had undergone a surgical procedure to manage their $\mathrm{TN}$. The median time since last surgery, based on 21 participants for whom these data were available, was about 3 years. The most common surgery was MVD (38/52; 73\%) with 8 of these patients also having another type of surgery (Table 6). MVD was also the most recent surgery for most patients (33/52).
Overall patients had a positive post-surgical experience, with 36/52 (69\%) of all patients who had surgery reporting much better pain relief including 21/52 $(40 \%)$ reporting complete pain relief (Table 7). Of those who had MVD only, 17/30 (57\%) reported $100 \%$ pain relief and 22/30 (73\%) felt much better. However, among all patients who underwent surgery $7 / 52(13 \%)$ patients felt no relief. Ten of the $52(19 \%)$ had worsening of pain or no change in pain postsurgery. However, none of the patients reported having much worse pain after surgery and of those who had surgery, 41 (79\%) stated surgery was better than staying on pain medications. When patients were asked about their most recent surgery, 15/52 (29\%) of respondents reported complications, the most common of which were cerebrospinal fluid leak, unsteady on

Table 2 Pain Experience and Medication/Surgery - N(\%)

\begin{tabular}{lllll}
\hline Pain Experience in Past $\mathbf{4}$ Weeks $^{\mathbf{a}}$ & Taking Medication & Not Taking Medication & Had Surgery & No Surgery \\
\hline None $(N=69)$ & $32(46 \%)$ & $37(54 \%)$ & $37(54 \%)$ & $31(45 \%)$ \\
Yes $(n=59)$ & $51(86 \%)$ & $8(14 \%)$ & $14(24 \%)$ & $45(76 \%)$ \\
\hline
\end{tabular}

${ }^{\mathrm{a}} 1$ participant had missing data for surgery 
Table 3 History of Specific Medication Use for TN, n (\%)

\begin{tabular}{lllll}
\hline Medication, $(\boldsymbol{N}=\mathbf{1 2 9})$ & $\begin{array}{l}\text { Never } \\
\text { took }\end{array}$ & $\begin{array}{l}\text { Currently } \\
\text { taking }\end{array}$ & $\begin{array}{l}\text { Took but stopped within last } \mathbf{6} \\
\text { months }\end{array}$ & $\begin{array}{l}\text { Took but stopped more than } \mathbf{6} \\
\text { months ago }\end{array}$ \\
\hline Carbamazepine $^{\prime}$ & $18(14)$ & $30(23)$ & $5(4)$ & $76(59)$ \\
Oxcarbazepine $^{\mathrm{a}}$ & $43(34)$ & $39(31)$ & $9(7)$ & $37(29)$ \\
Gabapentin $^{\mathrm{a}}$ & $71(56)$ & $8(6)$ & 0 & $49(38)$ \\
Pregabalin $^{\mathrm{a}}$ & $92(72)$ & $11(9)$ & $2(2)$ & $23(18)$ \\
Phenytoin $^{\mathrm{a}}$ & $119(93)$ & $2(2)$ & $1(1)$ & $6(5)$ \\
Amitriptyline $^{\mathrm{a}}$ & $97(76)$ & $1(1)$ & $1(1)$ & $29(23)$ \\
Nortriptyline $^{\mathrm{a}}$ & $119(93)$ & $1(1)$ & $1(1)$ & $7(6)$ \\
Drug patches or lidocaine cream, $_{\text {spray }^{\mathrm{a}}}$ & $111(87)$ & $3(2)$ & $2(2)$ & $12(9)$ \\
Oppioids, eg, morphine, fentanyl $_{\text {patches }^{\mathrm{a}}}$ & $116(91)$ & $2(2)$ & $1(1)$ & $9(7)$ \\
Tramadol $^{\mathrm{a}}$ & $114(89)$ & $2(2)$ & $2(2)$ & $10(8)$ \\
NSAIDs for TN $^{\mathrm{b}}$ & $86(68)$ & $7(6)$ & $3(2)$ & $31(24)$ \\
Lamotrigine $^{\mathrm{a}}$ & $94(73)$ & $21(16)$ & $6(5)$ & $7(6)$ \\
Duloxetine $^{\mathrm{a}}$ & $124(97)$ & $2(2)$ & 0 & $2(2)$ \\
Botulinum Toxin $^{\mathrm{a}}$ & $127(99)$ & $1(1)$ & 0 & 0 \\
\hline
\end{tabular}

${ }^{\mathrm{a} M i s s i n g} \mathrm{n}=1 ;{ }^{\mathrm{b}}$ Missing $n=2$

NSAIDs non-steroidal anti-inflammatory drugs; $T N$ trigeminal neuralgia

feet, and headache; other complications reported were ringing in the ears, dizziness, and facial weakness.

Pain medications for TN were being taken by $25 / 52$ (48\%) who had undergone surgery (Table 6), and $17 /$ 52 (33\%) reported new and different facial pain. Of the 17 patients with new and different facial pain, almost half reported recurring pain within 2 months or less of surgery $(n=8)$. Even with MVD, 5/38 (13\%) required repeat MVD surgery, and all 5 of these patients still had some interference in ADLs as assessed by the Penn-FPS-R.

\section{6-month pain experience}

Of 53 respondents who reported pain in the past 6 months, 7 (13\%) felt daily pain while 14 (26\%) had painfree periods for months. A total of 39 of these 53 participants had pain in the past 4 weeks (Table 6).

\section{Disease impact: PRO measures}

Those with current pain interference as assessed by the PENN-FPS-R (77/127, 61\%) showed numerically lower (ie, worse) quality of life scores than those reporting no pain interference on the EQ-5D-5L index $(0.80, \mathrm{SD}=0.214$ versus $0.96, \mathrm{SD}=0.141$, respectively). The EQ-VAS showed similar results: those with current pain interference had lower global health scores $(65.9, \mathrm{SD}=25.46)$ than those who did not $(82.9, \mathrm{SD}=21.39)$. Patients who were not on medication and those who had undergone an MVD had numerically better overall outcomes on the PGIC and BPI measures than those who were on medication and those who did not have MVD. Patients with no current pain interference scores also reported numerically better scores on the BPI-SF pain interference scale $(2.10, \mathrm{SD}=2.436$ versus $0.18, \mathrm{SD}=0.628$ ). In the PGIC measure, which asked participants if they experienced improvement since starting treatment at this clinic, $79 \%$ expressed their

Table 4 Historical Medication Use for TN

\begin{tabular}{|c|c|c|c|c|}
\hline & \multirow[b]{2}{*}{$\begin{array}{l}\text { Total } \\
(N=129)\end{array}$} & \multicolumn{3}{|c|}{ Current Medication Use } \\
\hline & & $\begin{array}{l}\text { Monotherapy } \\
(N=49)\end{array}$ & $\begin{array}{l}\text { Polytherapy* } \\
(N=35)\end{array}$ & $\begin{array}{l}\text { No Current Medication } \\
(N=45)\end{array}$ \\
\hline \multicolumn{5}{|c|}{ Number of Medications Taken for TN Ever } \\
\hline Mean (SD) & $3.7(2.2)$ & $3.0(1.7)$ & $4.8(2.5)$ & $3.5(2.10)$ \\
\hline Median (IQR) & $3.0(2,5)$ & $3.0(2,4)$ & $5.0(3,6)$ & $3.0(2,4)$ \\
\hline Min-Max & $1-13$ & $1-8$ & $2-13$ & $1-12$ \\
\hline
\end{tabular}

Nearly half of respondents $(62 / 129 ; 48 \%)$ had at some point discontinued a medication due to lack of efficacy and $51 / 129$ (40\%) had discontinued due to side effects (Table 5) 
Table 5 Reasons for Medication Discontinuation ${ }^{a}$

\begin{tabular}{ll}
\hline & Number of Patients, $\mathbf{n}(\%)$ \\
\hline Total Patients (N) & 129 \\
Not relieving pain & $62(48)$ \\
Changed to a different drug & $59(46)$ \\
Difficult side effects & $51(40)$ \\
No longer needed (remission) & $28(22)$ \\
No longer needed (surgery) & $28(22)$ \\
Other reason & $21(16)$ \\
\hline
\end{tabular}

Patients could select more than one reason

condition had very much or much improved with 10 (8\%) reporting worsening of their condition. The HADS anxiety and depression scores, on average, were within the normal range (0 to 7) for both those who had experienced pain episodes in the past 4 weeks and those who had not.

A summary of PRO measure results by TN attack frequency is shown in Table 8. A summary of PRO measure results for medication and surgical history is included in Supplement 1, Trigeminal Neuralgia PRO Scores Medication and Surgery History.

\section{Discussion}

This cross-sectional study, conducted at a specialist facial pain treatment facility, consisted of a subpopulation of patients of an earlier study [6]. The study yielded several key findings. Overall, the results indicate that a multidisciplinary care pathway can produce substantial benefit in a majority of patients, as evidenced by $79 \%$ of patients reporting improvement in the PGIC measure since beginning of treatment at this clinic. In addition, the average HADS score at the time of survey was within the normal range; this is encouraging in view of the fact that a prior study of 225 patients at this center (that included all 129 respondents of this study) was conducted at an earlier timepoint, and showed 36\% had mild to severe depression and over $50 \%$ had anxiety as found on HADS [6]. This apparent reduction in anxiety and depression over time for the survey population is notable, given that a recent epidemiological study showed a rise in anxiety, depression and poor sleep after a diagnosis of TN [23].

Even though most patients reported improvement since beginning treatment, the majority were still on medications, with $42 \%$ of those individuals on polytherapy. At the time of the survey patients were taking an average of 1.1 medications, however overall treatment history shows patients on average had taken 3.7 drugs for $\mathrm{TN}$, and as many as 13 different drugs. During the course of treatment a substantial percentage of patients had discontinued 1 or more medication(s) for various reasons, frequently due to lack of efficacy or tolerability. While polytherapy can yield clinical benefits, it also carries increased risk of AEs and drug interactions [24-26]. A study by Di Stefano et al. [9] found that carbamazepine and oxcarbazepine, the 2 medications commonly recommended as first-line therapy for TN, produce side effects that can lead to treatment withdrawal. In addition,

Table 6 Pain Control by Pain, Medication and Surgical History

\begin{tabular}{|c|c|c|c|c|c|c|c|c|c|c|}
\hline \multirow[b]{2}{*}{ Item } & \multirow[b]{2}{*}{ Overall } & \multicolumn{2}{|l|}{ Pain } & \multicolumn{3}{|l|}{ Medication } & \multicolumn{4}{|c|}{ Surgery $^{\mathbf{b}}$} \\
\hline & & $\begin{array}{l}\text { Any attacks } \\
\text { in the past } \\
4 \text { weeks }\end{array}$ & $\begin{array}{l}\text { No TN in } \\
\text { the past } \\
4 \text { weeks }\end{array}$ & $\begin{array}{l}\text { Current } \\
\text { monotherapy }\end{array}$ & $\begin{array}{l}\text { Current } \\
\text { polytherapy }\end{array}$ & $\begin{array}{l}\text { Took } \\
\text { but } \\
\text { Stopped }\end{array}$ & $\begin{array}{l}\text { No } \\
\text { surgery }\end{array}$ & $\begin{array}{l}\text { MVD } \\
\text { only }\end{array}$ & $\begin{array}{l}\text { Ablative } \\
\text { surgery }\end{array}$ & $\begin{array}{l}\text { MVD + } \\
\text { Ablative } \\
\text { surgery }\end{array}$ \\
\hline \multicolumn{11}{|l|}{ Current Medication, n (\%) } \\
\hline & $\begin{array}{l}N= \\
129\end{array}$ & $n=59$ & $n=69$ & $n=49$ & $n=35$ & $n=45$ & $N=77$ & $\begin{array}{l}n= \\
30\end{array}$ & $n=13$ & $n=8$ \\
\hline Currently Taking Medication ${ }^{a}$ & $84(65)$ & $51(40)$ & $32(25)$ & $49(38)$ & $35(27)$ & 0 & $59(46)$ & $10(8)$ & $9(7)$ & $6(5)$ \\
\hline $\begin{array}{l}\text { Not currently taking } \\
\text { medication to manage pain }\end{array}$ & $45(35)$ & $8(6)$ & $37(29)$ & 0 & 0 & $45(35)$ & $18(14)$ & $\begin{array}{l}20 \\
(16)\end{array}$ & $4(3)$ & $2(2)$ \\
\hline \multicolumn{11}{|c|}{ Frequency Pattern of Pain experienced in past 6 months ${ }^{c} ; n(\%)$} \\
\hline $\mathbf{N}$ & $n=53$ & $n=39$ & $n=14$ & $n=24$ & $n=18$ & $n=11$ & $n=41$ & $n=6$ & $n=4$ & $n=2$ \\
\hline Daily & $7(13)$ & $6(15)$ & $1(7)$ & $4(17)$ & $3(17)$ & NA & $4(10)$ & $2(33)$ & NA & $1(50)$ \\
\hline $\begin{array}{l}\text { For days, then I have days or } \\
\text { weeks free of TN }\end{array}$ & $17(32)$ & $10(26)$ & $7(50)$ & $5(21)$ & $6(33)$ & $6(55)$ & $13(32)$ & $2(33)$ & $2(50)$ & 0 \\
\hline $\begin{array}{l}\text { For weeks, then I have days } \\
\text { or weeks free of TN }\end{array}$ & $4(8)$ & $4(10)$ & 0 & $3(13)$ & $1(6)$ & NA & $4(10)$ & 0 & 0 & 0 \\
\hline $\begin{array}{l}\text { I have months completely } \\
\text { free of TN }\end{array}$ & $14(26)$ & $10(26)$ & $4(29)$ & $7(29)$ & $4(22)$ & $3(27)$ & $11(27)$ & 0 & $2(50)$ & $1(50)$ \\
\hline $\begin{array}{l}\text { I have months free of TN } \\
\text { attacks but with a dull ache } \\
\text { in the background }\end{array}$ & $11(21)$ & $9(23)$ & $2(14)$ & $5(21)$ & $4(22)$ & $2(18)$ & $9(22)$ & $2(33)$ & 0 & 0 \\
\hline
\end{tabular}


Table 7 Pain Experience by Surgical History

\begin{tabular}{|c|c|c|c|c|}
\hline & $\begin{array}{l}\text { Overall } \\
n=52^{\mathrm{a}}\end{array}$ & $\begin{array}{l}\text { MVD } \\
n=30\end{array}$ & $\begin{array}{l}\text { Ablative surgery } \\
n=13\end{array}$ & $\begin{array}{l}\text { MVD + Ablative surgery } \\
n=8\end{array}$ \\
\hline \multicolumn{5}{|c|}{ How does the current pain feel now compared to before the surgery? $n(\%)$} \\
\hline Somewhat worse & $6(12)$ & $4(14)$ & $1(8)$ & $1(13)$ \\
\hline Stayed the same & $4(8)$ & $1(3)$ & $3(23)$ & 0 \\
\hline Somewhat better & $6(12)$ & $3(10)$ & 0 & $3(38)$ \\
\hline Much better & $36(69)$ & $22(73)$ & $9(69)$ & $4(50)$ \\
\hline 0\% Pain Relief & $7(13)$ & $3(10)$ & $4(31)$ & 0 \\
\hline 100\% Pain Relief & $21(40)$ & $17(57)$ & $2(15)$ & $2(25)$ \\
\hline \multicolumn{5}{|c|}{ Currently taking any medication, $\mathrm{n}(\%)$} \\
\hline Currently taking monotherapy & $8(15)$ & $2(7)$ & $6(46)$ & 0 \\
\hline Currently taking polytherapy & $17(33)$ & $8(27)$ & $3(23)$ & $6(75)$ \\
\hline
\end{tabular}

${ }^{\mathrm{a}} 1$ missing: patient had peripheral cryotherapy before attending specialist center

one study reported a sizable fraction (as high as 19\%) of patients experience an attenuation of the effect of carbamazepine on managing their pain over time [15], though it is not known whether this result is due to natural progression of the condition, development of resistance, or some other factor.

In this study, although surgery, especially MVD, often alleviated pain in many patients, this was not always the case: 10/52 (18\%) of respondents reported somewhat worse or same pain post-surgery. Additionally, a proportion of patients required multiple surgeries and several patients experienced complications post-surgery. Further, a sizable percentage of patients continued to use medications after surgery. Also, the long-term outcome of surgery is unknown and can be deduced only from a longitudinal follow-up of this patient population. Published reports have shown that while the short-term success rate of surgery is high, there is a risk of recurrence even when initial outcomes are good, especially over time. In some cases, patients require repeat surgery or return to medications. In a follow-up study of TN patients who had MVD with a median follow-up period of 9.7 years, some patients were found to relapse even though they had immediate postsurgery relief [27]. While recurrence of pain is more likely with ablative procedures than MVD, findings from a prior study that tracked patients who had undergone MVD showed that $16.6 \%$ of them experienced a recurrence after MVD at 5 years [28]. In addition, in this survey many patients reported inadequate or no pain relief post-surgery, indicating that there are intractable cases of TN.

It should be noted that the favorable results in this study were obtained at a facility able to provide a very high level of care that consists of the concurrent involvement of healthcare practitioners from multiple disciplines, thorough monitoring of patients using established PROs, as well as prompt and thorough pharmacological and surgical interventions; this level of care may not be feasible at all conventional treatment centers [29]. Traditionally, TN has been regarded as a progressive condition that for most patients worsens over time [30,31]. Even specialist centers not utilizing the multidisciplinary approach may fail to provide adequate care: prior to enrollment, $80 \%$ of patients who participated in the earlier study experienced inadequate disease management [6]. Even though only 40\% of patients in the study population had surgery, all patients in the study were offered surgery, which in some centers may only be recommended later in the treatment pathway. Neurologists have suggested that surgical treatments should be reserved for patients with intractable $\mathrm{TN}$ and who have used at least 3 drugs in adequate doses [32]. As such, the favorable outcomes seen in this study may not be generalizable to all UK patients with TN.

To the authors' knowledge, this is the first study to extensively explore the interrelated aspects of pain interference, treatment history, and patient-reported disease impact in patients who were managed following treatment recommendations of the American Academy of Neurology and the European Federation of Neurological Societies [18]. This study's findings are supported by a study by Heinskou et al. [16], which also showed that a highly specialized center utilizing a multidisciplinary approach achieved improvement in their patients' disease status. This approach is recommended in the updated guidelines [8]. A recent systematic review of outcomes used in 467 TN studies highlights how few studies report on domains such as physical $(n=46)$ and emotional functioning $(n=$ 17 ) and only 35 studies collected data on patient satisfaction [33]. This study adds a breadth of information to the relatively limited prior research on these topics. Another strength of this study is that among the eligible patients initially selected for the study, no obvious difference between respondents and non-respondents was observed, indicating low risk of selection bias in the survey cohort. To further reduce bias, data collection was carried out by 
Table 8 PRO Scores by TN Attack Frequency

\begin{tabular}{|c|c|c|c|}
\hline \multirow[b]{2}{*}{ Measure } & \multicolumn{3}{|l|}{ Pain } \\
\hline & Overall & Any attacks in the past 4 weeks & No TN in the past 4 weeks \\
\hline Penn-FPS-R & $n=127$ & $n=58$ & $n=68$ \\
\hline Mean (SD) & $22.0(29.5)$ & $39.1(32.1)$ & $7.6(16.9)$ \\
\hline Median (IQR) & $8.0(0.0,36.0)$ & $34.0(10.0,64.0)$ & $0.0(0.0,9.5)$ \\
\hline Min/Max & $0.0 / 120.0$ & $0.0 / 120.0$ & $0.0 / 89.0$ \\
\hline PGIC, n (\%) & $n=129$ & $n=59$ & $n=69$ \\
\hline Very much improved & $63(49)$ & $14(24)$ & $48(70)$ \\
\hline Much improved & $39(30)$ & $26(44)$ & $13(19)$ \\
\hline Minimally improved & $11(9)$ & $9(15)$ & $2(3)$ \\
\hline No change & $6(5)$ & $2(3)$ & $4(6)$ \\
\hline Minimally worse & $1(1)$ & 0 & $1(1)$ \\
\hline Much worse & $5(4)$ & $4(7)$ & $1(1)$ \\
\hline Very much worse & $4(3)$ & $4(7)$ & 0 \\
\hline BPI-SF (Intensity) & $n=129$ & $n=59$ & $n=69$ \\
\hline Mean (SD) & $1.39(1.77)$ & $2.62(1.89)$ & $0.36(0.67)$ \\
\hline Median (IQR) & $0.50(0.0,2.25)$ & $2.50(1.0,4.3)$ & $0.00(0.0,0.50)$ \\
\hline Min/Max & $0.0 / 7.8$ & $0.0 / 7.8$ & $0.0 / 2.5$ \\
\hline BPI-SF (Interference) & $n=129$ & $n=59$ & $n=69$ \\
\hline Mean (SD) & $1.05(1.96)$ & $2.10(2.44)$ & $0.18(0.63)$ \\
\hline Median (IQR) & $0.00(0.00,1.14)$ & $1.14(0.00,3.86)$ & $0.00(0.00,0.00)$ \\
\hline Min/Max & $0.0 / 9.7$ & $0.0 / 9.7$ & $0.0 / 3.7$ \\
\hline EQ-5D-5L -HUI UK weights & $n=129$ & $n=59$ & $n=69$ \\
\hline Mean (SD) & $0.864(0.2)$ & $0.790(0.2)$ & $0.927(0.2)$ \\
\hline Median (IQR) & $0.939(0.816,1.000)$ & $0.841(0.741,0.939)$ & $1.000(0.924,1.000)$ \\
\hline Min/Max & $-0.075 / 1.000$ & $0.049 / 1.000$ & $-0.075 / 1.000$ \\
\hline EQ-5D-5L-VAS & $n=129$ & $n=59$ & $n=69$ \\
\hline Mean (SD) & $72.6(25.2)$ & $66.4(24.3)$ & $77.5(24.9)$ \\
\hline Median (IQR) & $81.0(55.0,94.0)$ & $70.0(50.0,88.0)$ & $90.0(68.0,95.0)$ \\
\hline Min/Max & $10 / 100$ & $13 / 100$ & $10 / 100$ \\
\hline HADS Anxiety & $n=128$ & $n=58$ & $n=69$ \\
\hline Mean (SD) & $5.4(4.3)$ & $6.7(4.6)$ & $4.3(3.8)$ \\
\hline Median (IQR) & $5.0(2.0,8.0)$ & $6.0(4.0,10.0)$ & $3.0(1.0,6.0)$ \\
\hline Min/Max & $0.0 / 21.0$ & $0.0 / 21.0$ & $0.0 / 15.0$ \\
\hline HADS Depression & $n=128$ & $n=58$ & $n=69$ \\
\hline Mean (SD) & $3.7(3.8)$ & $5.1(5.4)$ & $2.6(3.0)$ \\
\hline Median (IQR) & $2.0(1.0,5.0)$ & $4.0(0.0,9.0)$ & $1.0(0.0,4.0)$ \\
\hline Min/Max & $0.0 / 19.0$ & $0.0 / 19.0$ & $0.0 / 13.0$ \\
\hline
\end{tabular}

Note: in some cases component numbers may not add up to total number due to missing data

a third party rather than by the care providers at the treatment unit, as suggested by Akram et al. [34] Moreover, although the results reported above are cross-sectional, these data can be combined with survey data collected at an earlier timepoint from the same clinical cohort to assess longitudinal trends.
This study has some limitations. The chief limitation is that because TN is an episodic disease, the durability of pain relief is difficult to ascertain from a cross-sectional survey and it is likely to underestimate the impact of TN. Further studies with broader cohorts and data collection at multiple time points could expand upon the results presented above to account for the episodic nature of the 
disease and to understand the impact of TN in different patient populations. Another limitation is that because this study was conducted at a specialist multidisciplinary facility, data obtained in this study are unlikely to be applicable to the general UK TN patient population. This study also did not capture drug dosage information, and so could not assess whether those patients who had undergone surgery and were still taking medications were able to use lower doses post-surgery. Finally, the PGIC asked about change in TN since treatment began at this clinic. Given that participants had been in treatment for an average of more than 6 years, this long recall period may compromise the reliability of their responses. The response rate may have been affected by patients' unfamiliarity with completing online surveys and the lack of suitable IT skills.

\section{Conclusions}

These results, in conjunction with previously published results [16], indicate that a multidisciplinary care pathway is the desirable approach for all TN patients. However, it may be logistically not achievable, as conventional treatment centers may not have the resources to implement this pathway. Additionally, despite the high level of care achievable at these specialized treatment centers, there remains substantial unmet need for pain management among patients with TN. Pharmacological treatments can be effective but can have considerable drawbacks. Further, while surgery is an option when medication is not advisable or not effective, not all patients are eligible for or willing to undergo surgery and even the most effective surgery, MVD, is not successful in all cases. It is crucial that patients are aware of all available options and can change their management plans quickly depending on the status of their TN. The high numbers of current or prior medications, residual pain or complications despite surgical and/or medical interventions, and reduced QoL in those with current pain interference highlights the BOI of $\mathrm{TN}$ and the remaining unmet medical need. Thus, these findings support the development of additional treatment options that may result in less drug discontinuation, offer more alternatives to patients unwilling to undergo or ineligible for surgery, and be easily administered at conventional facilities. Finally, these results suggest a need for more personalization of medication use in order to obtain maximum efficacy and improved tolerability.

\section{Supplementary Information}

The online version contains supplementary material available at https://doi. org/10.1186/s10194-020-01198-z.

Additional file 1. TN PRO Scores Medication and Surgery History

\section{Abbreviations}

ADLs: Activities of daily living; AED: Antiepileptic drug; BOI: Burden of illness; BPI-SF: Brief Pain Inventory - Short Form; EQ-5D-5L: EuroQol-5 Dimension-5
Level; EQ-VAS: EuroQol Visual Analog Scale; HADS: Hospital Anxiety and Depression Scale; MVD: Microvascular decompression; PENN-FPS-R: PennFacial Pain Scale-Revised; PGIC: The Patient Global Impression of Change; QoL: Quality of life; TN: Trigeminal neuralgia

\section{Acknowledgements}

Medical writing and editorial assistance under the authors' guidance was provided by Dr. Amlan RayChaudhury (Clinical Outcomes Solutions, Chicago, USA). Programming assistance was provided by Hailin Yu (Clinical Outcomes Solutions, Chicago, USA).

\section{Authors' contributions}

LOC - Led manuscript development. Contributed to design of survey instrument, study design and analysis plan, and interpretation of results. LF Led analysis planning and execution, contributed to the interpretation of results and manuscript development. LVI - Contributed to design of survey instrument, study design and analysis plan, interpretation of results, and manuscript development. TS - Contributed to study design and analysis plan, interpretation of results, and manuscript development. KG Contributed to analysis plan, interpretation of results, and manuscript development. $\mathrm{CH}$ - Contributed to study design and manuscript development. JZ - Led development of survey instrument. Contributed to study design and analysis plan, interpretation of results, and manuscript development. All authors have reviewed and approved the final version.

\section{Funding}

This study was funded by Biogen. JZ undertook this work at UCL/UCLHT which received a proportion of funding from the Department of Health's National Institute for Health Research (NIHR) Biomedical Research Centre funding scheme. Funding for extracting data from paper records was provided by the Facial Pain Research Foundation.

\section{Availability of data and materials}

Patients with TN at a multidisciplinary facial pain clinic within a London teaching hospital were invited to complete a survey developed by the authors. The survey included items about pain interference, history and experience of medication use, history and experience of surgery related to TN, and various PRO measures. The survey data are not publicly available. The actual questionnaire used is available upon request to the authors.

\section{Ethics approval and consent to participate}

Full ethics approval for a cohort study was granted by London - South East Research Ethics Committee 07/MRE01138 in June 2007. In December 2017, the ethics committee approved an amendment for the survey to be converted from a paper version into an electronic format.

\section{Consent for publication}

Not applicable.

\section{Competing interests}

Lisa Vinikoor-Imler and Lasair O'Callaghan are and Kathryn Giblin was employees of Biogen at the time of this manuscript preparation and own stock stock options at Biogen. Kathryn Giblin is currently an employee of Sarepta Therapeutics, Inc. Lysbeth Floden, Tara Symonds, and Chris Hartford are employees of Clinical Outcomes Solutions, which received funding from Biogen to conduct the study described here. Joanna Zakrzewska has a consultancy agreement with Biogen.

\section{Author details}

${ }^{1}$ Biogen, 225 Binney St, Cambridge, MA 02142, USA. ${ }^{2}$ Clinical Outcomes Solutions, 1820 E. River Rd., Suite 220, Tucson, AZ 85718, USA. ${ }^{3}$ Clinical Outcomes Solutions, Unit 68, Basepoint, Shearway Road, Shearway Business Park, Folkestone, Kent CT19 4RH, UK. ${ }^{4}$ Formerly Biogen, 225 Binney St, Cambridge, MA 02142, USA. ${ }^{5}$ Royal National ENT \& Eastman Dental Hospitals, 4th Floor Central, 250 Euston Road, London NW1 2PQ, UK. ${ }^{6}$ UCLH NHS Foundation Trust, Oral theme of the UCL/UCLH NIHR Biomedical Research Centre UK, London, UK. 
Received: 1 September 2020 Accepted: 29 October 2020

Published online: 10 November 2020

\section{References}

1. Silva M, Ouanounou A (2020) Trigeminal neuralgia: etiology, diagnosis, and treatment. SN Comprehensive Clin Med:1-8

2. Cruccu G, Finnerup NB, Jensen TS, Scholz J, Sindou M, Svensson P et al (2016) Trigeminal neuralgia: new classification and diagnostic grading for practice and research. Neurology. 87(2):220-228

3. NINDS. National Institute of Neurological Disorders and Stroke. Trigeminal Neuralgia Information Page. Available at https://www.ninds.nih.gov/Disorders/ All-Disorders/Trigeminal-Neuralgia-Information-Page. Accessed 14 Mar 2020 [

4. De Toledo IP, Conti Reus J, Fernandes M, Porporatti AL, Peres MA Takaschima A et al (2016) Prevalence of trigeminal neuralgia: a systematic review. J Am Dent Assoc 147(7):570-576 e2

5. Melek LN, Devine M, Renton T (2018) The psychosocial impact of orofacial pain in trigeminal neuralgia patients: a systematic review. Int J Oral Maxillofac Surg 47(7):869-878

6. Zakrzewska JM, Wu J, Mon-Williams M, Phillips N, Pavitt SH (2017) Evaluating the impact of trigeminal neuralgia. Pain. 158(6):1166-1174

7. Antonaci F, Arceri S, Rakusa M, Mitsikostas D, Milanov I, Todorov V et al (2020) Pitfals in recognition and management of trigeminal neuralgia. J Headache Pain 21(1):1-8

8. Bendtsen L, Zakrzewska JM, Abbott J, Braschinsky M, Di Stefano G, Donnet A et al (2019) European academy of neurology guideline on trigeminal neuralgia. Eur J Neurol 26(6):831-849

9. Di Stefano G, La Cesa S, Truini A, Cruccu G (2014) Natural history and outcome of 200 outpatients with classical trigeminal neuralgia treated with carbamazepine or oxcarbazepine in a tertiary Centre for neuropathic pain. J Headache Pain. 15:34

10. Heinskou T, Maarbjerg S, Rochat P, Wolfram F, Jensen RH, Bendtsen L (2015) Trigeminal neuralgia--a coherent cross-specialty management program. J Headache Pain 16:66

11. Zakrzewska JM, Wu N, Lee JYK, Werneburg B, Hoffman D, Liu Y (2018) Characterizing treatment utilization patterns for trigeminal neuralgia in the United States. Clin J Pain 34(8):691-699

12. Tentolouris-Piperas V, Lee G, Reading J, O'Keeffe AG, Zakrzewska JM, Cregg $R$ (2018) Adverse effects of anti-epileptics in trigeminal neuralgiform pain. Acta Neurol Scand 137(6):566-574

13. Spina A, Mortini P, Alemanno F, Houdayer E, lannaccone S (2017) Trigeminal neuralgia: toward a multimodal approach. World Neurosurg 103:220-230

14. Katusic S, Williams DB, Beard CM, Bergstralh EJ, Kurland LT (1991) Epidemiology and clinical features of idiopathic trigeminal neuralgia and glossopharyngeal neuralgia: similarities and differences, Rochester, Minnesota, 1945-1984. Neuroepidemiology. 10(5-6):276-281

15. Taylor JC, Brauer S, Espir ML (1981) Long-term treatment of trigeminal neuralgia with carbamazepine. Postgrad Med J 57(663):16-18

16. Heinskou TB, Maarbjerg S, Wolfram F, Rochat P, Brennum J, Olesen J et al (2019) Favourable prognosis of trigeminal neuralgia when enrolled in a multidisciplinary management program - a two-year prospective real-life study. J Headache Pain. 20(1):23

17. Ghiai A, Mohamed T-Y, Hussain M, Hayes E, Zakrzewska JM (2019) The role of a clinical nurse specialist in managing patients with trigeminal neuralgia. Br J Pain 2049463719892027

18. Gronseth G, Cruccu G, Alksne J, Argoff C, Brainin M, Burchiel K et al (2008) Practice parameter: the diagnostic evaluation and treatment of trigeminal neuralgia (an evidence-based review): report of the quality standards Subcommittee of the American Academy of neurology and the European Federation of Neurological Societies. Neurology. 71(15):1183-1190

19. Symonds T, Randall JA, Hoffman DL, Zakrzewska JM, Gehringer W, Lee JY (2018) Measuring the impact of trigeminal neuralgia pain: the Penn facial pain scale-revised. J Pain Res 11:1067-1073

20. Fischer D, Stewart AL, Bloch DA, Lorig K, Laurent D, Holman H (1999) Capturing the patient's view of change as a clinical outcome measure. JAMA. 282(12):1157-1162

21. Sandhu SK, Halpern CH, Vakhshori V, Mirsaeedi-Farahani K, Farrar JT, Lee JY (2015) Brief pain inventory--facial minimum clinically important difference. J Neurosurg 122(1):180-190

22. Zigmond AS, Snaith RP (1983) The hospital anxiety and depression scale. Acta Psychiatr Scand 67(6):361-370
23. Wu TH, Hu LY, Lu T, Chen PM, Chen HJ, Shen CC et al (2015) Risk of psychiatric disorders following trigeminal neuralgia: a nationwide population-based retrospective cohort study. J Headache Pain 16:64

24. Andrew T, Milinis K, Baker G, Wieshmann U (2012) Self reported adverse effects of mono and polytherapy for epilepsy. Seizure. 21(8):610-613

25. Diaz RA, Sancho J, Serratosa J (2008) Antiepileptic drug interactions. Neurologist. 14(6 Suppl 1):S55-S65

26. Witt JA, Helmstaedter C (2017) How can we overcome neuropsychological adverse effects of antiepileptic drugs? Expert Opin Pharmacother 18(6):551-554

27. Oesman C, Mooij JJ (2011) Long-term follow-up of microvascular decompression for trigeminal neuralgia. Skull Base 21(5):313-322

28. Jafree DJ, Zakrzewska JM (2018) Long-term pain relief at five years after medical, repeat surgical procedures or no management for recurrence of trigeminal neuralgia after microvascular decompression: analysis of a historical cohort. Br J Neurosurg:1-6

29. Besi E, Zakrzewska JM (2020) Trigeminal neuralgia and its variants Management and diagnosis. Oral Surgery 13:404

30. TNAUK. Trigeminal Neuralgia Association UK. https://www.tna.org.uk/whatis-trigeminal-neuralgia/. Accessed 10 June 2020 [

31. NINDS. National Institute of Neurological Diseases and Stroke. https://www. ninds.nih.gov/Disorders/Patient-Caregiver-Education/Fact-Sheets/TrigeminalNeuralgia-Fact-Sheet Accessed 10 June 2020

32. Obermann M (2010) Treatment options in trigeminal neuralgia. Ther Adv Neurol Disord 3(2):107-115

33. Nova CV, Zakrzewska JM, Baker SR, Riordain RN (2020) Treatment outcomes in trigeminal neuralgia-a systematic review of domains. Dimensions and Measures World Neurosurg X 6:100070

34. Akram H, Mirza B, Kitchen N, Zakrzewska JM (2013) Proposal for evaluating the quality of reports of surgical interventions in the treatment of trigeminal neuralgia: the surgical trigeminal neuralgia score. Neurosurg Focus 35(3):E3

\section{Publisher's Note}

Springer Nature remains neutral with regard to jurisdictional claims in published maps and institutional affiliations.

Ready to submit your research? Choose BMC and benefit from:

- fast, convenient online submission

- thorough peer review by experienced researchers in your field

- rapid publication on acceptance

- support for research data, including large and complex data types

- gold Open Access which fosters wider collaboration and increased citations

- maximum visibility for your research: over $100 \mathrm{M}$ website views per year

At BMC, research is always in progress.

Learn more biomedcentral.com/submissions 